\title{
A EXPERIÊNCIA TRANSFORMADORA DA EDUCAÇÃO NO CONTEXTO DA PANDEMIA
}

\author{
Neide Cavalcante Guedes ${ }^{\mathrm{i}}$ \\ Tiago Pereira Gomes ${ }^{\text {ii }}$
}

\begin{abstract}
RESUMO: O artigo trata da desigualdade social, domínio das tecnologias, e a presença da igualdade e da equidade na escola e na academia. Trazemos as questões estruturais que travam as atividades educacionais, discutimos igualdade e equidade na perspectiva de analisar a Lei e sua efetivação no que diz respeito ao sistema público de ensino e finalizamos com o estudo realizado pela Universidade Federal do Amazonas sobre a realização de Atividades Extracurriculares Especiais por meio das tecnologias. Em síntese, a pandemia mostra a real condição das instituições sociais tanto na educação quanto na saúde.
\end{abstract}

Palavras-chave: Igualdade; Equidade; Educação; Tecnologia; Pandemia.

\section{THE TRANSFORMING EXPERIENCE OF EDUCATION IN THE PANDEMIC CONTEXT}

\begin{abstract}
The article deals with social inequality, mastery of technologies, and the presence of equality and equity in schools and academia. We bring the structural issues that hinder educational activities, discuss equality and equity in the perspective of analyzing the Law and its effectiveness with regard to the public education system and conclude with the study carried out by the Federal University of Amazonas on the realization of Special Extracurricular Activities through technologies. In summary, the pandemic shows the real condition of social institutions in both education and health.
\end{abstract}

Keywords: Equality; Equity; Education; Technology; Pandemic.

\section{NOTAS INTRODUTÓRIAS}

O cenário educacional brasileiro vive hoje momentos de incertezas e angústia, tanto por parte dos docentes, independente do seu nível de atuação, quanto dos discentes, pela diversidade de contextos geográfico, social, educacional. O presente artigo objetiva refletir sobre elementos como: desigualdade social, domínio das tecnologias, acesso ao ambiente virtual, dentre outros, buscando identificar elementos que possam evidenciar a presença ou não da igualdade e da equidade no âmbito da escola e da academia.

Nessa perspectiva, um dos maiores desafios assumidos pelos docentes é o de ser capaz de desenvolver uma profissionalidade que não envolva processos de interação somente com/entre seus alunos, mas principalmente que seja capaz de expandir e envolver outros contextos para além da sala de aula, tendo em vista que essa prática isolada compromete o modo legítimo de desenvolver a prática docente. 
artes de

educar

Essa necessidade de interação com entidades múltiplas é importante considerando que a função educativa, seja no micro ou no macrossistema, já não se constitui de exclusividade do poder central cujas finalidades exclusivas se coloquem fora desse processo. (BARROSO, 2003) Assim, torna-se necessário resgatar para essa discussão conceitos como regulação e gerencialismo no sentido de que o papel formal do Estado enquanto gestor e orientador da vida social precisa assumir uma versão mais ampla capaz de integrar os diferentes agentes sociais presentes nas redes educativas, merecendo destaque o uso das tecnologias.

Esses conceitos sempre estiveram em evidência no âmbito de análise das políticas educacionais adotadas no Brasil, na América Latina e até mesmo em âmbito mundial, traduzindo diferentes formas de relações entre o Estado e a sociedade. Por esse viés entendemos que as transformações que se impõem no setor público e na sociedade civil introduzem uma nova forma de regulação social que, para Ball; Mainardes (2011), se constitui em um mecanismo de correção dos efeitos prejudiciais da atividade econômica projetada para produzir resultados socialmente desejados e funciona como regulação governamental para tratar dos efeitos negativos das relações de produção. Essa análise tornase substantiva não apenas para entender as atuais políticas educacionais, mas também as mudanças que vêm ocorrendo globalmente na educação, uma vez que, segundoBall; Mainardes (2011), essas transformações no campo educacional são também perpassadas pelas modificações que vêm ocorrendo no setor público.

O gerencialismo no campo educacional, conforme destacamShiroma; Campos (2006, p. 224), se constitui em "um movimento que tenta modificar não só a organização da escola, imprimir outra lógica ao funcionamento do sistema educacional [...]”, e visa, nomeadamente, "operar uma transformação na subjetividade dos educadores, por meio da implantação de mecanismos bastante objetivos de controle que afetam a organização, a avaliação e, portanto, a gestão do trabalho docente". Assim, ao desempenhar o importante papel de aniquilar os sistemas ético-profissionais que prevaleciam nas escolas, provoca a sua substituição por sistemas empresariais competitivos. Isso envolve "processos de institucionalização e desinstitucionalização", pois ao invés de ser uma mudança "de uma vez por todas", é um atrito constante, feito de mudanças incrementais maiores e menores, que são em grande número e discrepantes.

Este texto objetiva provocar reflexões sobre como os sistemas de ensino estão se adaptando às exigências impostas pela necessidade do isolamento social sem que haja prejuízo na continuidade das atividades de ensino e de aprendizagem, considerando as possíveis articulações que permanentemente são tecidas dentro e fora do espaço sistematizado 
da instituição educacional. Essa tessitura se abastece das possibilidades de estabelecer reflexões sobre as práticas cotidianas advindas das mais variadas trajetórias que foram sendo vivenciadas por esses sujeitos, como processos formativos diversos e a introdução do formato tecnológico como alternativa nas instituições de ensino brasileiras.

Nessa perspectiva de compreensão, o conhecimento se organiza a partir dos sujeitos; das relações que estabelecem entre si; dos meios de comunicação e dos processos utilizados para a sua propagação, que se configuram como uma rede sociotécnica a partir do hipertexto como modelo de construção.Assim, podemos inferir que conhecimento é um termo polissêmico e pode significar o sentido que atribuímos a informação enquanto ação, movimento, atividade.

O homem é um ser eminentemente social, e tem nas manifestações culturais as possibilidades de informações indispensáveis para o seu processo de desenvolvimento. Nesse sentido, a cultura agrega o conjunto de ferramentas que medeiam todas as suas experiências relacionais. Essas várias identidades são construções que se fazem com propriedades culturais adquiridas pelo sujeito por meio das relações sociais que envolvem a herança cultural, pois como bem esclarece Sodré (1996, p. 173), “a pessoa é o próprio ser humano enquanto invenção da cultura".

Nesse sentido,não podemos esquecer que a escola, como instituição social, desenvolve também uma função social, com atribuições baseadas nas necessidades que são socialmente produzidas, evidenciadas e solicitadas institucionalmente de modo que a formação escolar recebida pelos alunos atenda as exigências no âmbito social.

Essa escola materializa-se como espaço de relações políticas no qual se busca o diálogo público sobre o acesso e a utilização intencional do conhecimento, conforme o interesse dos grupos e sujeitos sociais, uma vez que essas múltiplas dimensões ao se articularem na dinâmica da educação escolar irão fazer desse espaço institucionalizado um organismo de cidadania, como estabelece a Lei de Diretrizes e Bases da Educação Nacional (Lei 9.394), art. $2^{\circ}$ :

Artigo $2^{\circ}$ - A educação, dever da família e do estado, inspirada nos princípios de liberdade e nos ideais e solidariedade humana, tem por finalidade o pleno desenvolvimento do educando, seu preparo para o exercício da cidadania e sua qualificação para o trabalho.

Considerando o que estabelece o texto legal, é fundamental compreender como os conceitos de igualdade $^{\mathrm{iii}}$ e equidade ${ }^{\mathrm{iv}}$ são percebidos e vivenciados no cotidiano dos 
estudantes brasileiros, diante da pandemia que assola o planeta. Nossa pretensão neste artigo é destacar inicialmente as questões estruturais que muitas vezes travam as atividades educacionais.Em seguida, discutir um pouco sobre igualdade e equidade na perspectiva de analisar a letra da Lei e sua efetivação no que diz respeito ao sistema público de ensino, estabelecendo um elo entre a universidade e o uso das tecnologias como suporte na condução das atividades educacionais, e finalizar trazendo dados do estado do Amazonas como forma de expressar as dificuldades, limites e desigualdades entre os sujeitos. Nosso posicionamento se inscreve na compreensão de que aescola brasileira em todas as suas etapas sempre enfrentou problemas de ordem estrutural, mas que nem sempre isso se constituía em obstáculo para a normalidade de suas ações.

Refletir sobre a educação pública brasileira e seus indicadores de desempenho nos encaminha a pensar a sociedade e suas diversidades, o que garante trabalhar as questões de equidade, visto que que se forem apenas pensadas as questões da igualdade, certamente não existirão meios para o atendimento efetivo das necessidades da educação pública.

O ser humano procura viver dignamente apesar de o grande desafio da humanidade se expressar na possibilidade de aceitar que todos, indistintamente, conquistem essa condição. Com esse entendimento reforçamos que a igualdade nada mais é do que tratar todos iguais e considerando o quanto cada um é diferente. No outro lado dessa discussão não podemos desprezar a equidade entre as pessoas, visto que o homem é um ser único, com limitações e dificuldades individuais. Isso faz com que se revele a obrigação de garantir os direitos de forma igual a todo cidadão, ponderando caso a caso, pois somente assim é possível atingir ou pelo menos se aproximar da justiça social.

Portanto, é relevante considerar que,trazendo para o campo das relações sociais, tanto a equidade quanto a igualdade constituem-se em princípios fundamentais da justiça social que são obtidos através da luta de classes e de sujeitos nos mais variados espaços sociais. Com esse entendimento, nos apoiamos em Mészáros (2002) quando trata que

[...] a condição prévia essencial da verdadeira igualdade é enfrentar com uma crítica radical a questão do modo inevitável de funcionamento do sistema estabelecido e sua correspondente estrutura de comando, que a priori exclui quaisquer expectativas de uma verdadeira igualdade (MÉSZÁROS, 2002, p. 289).

O autor chama a atenção para o fato de que o próprio sistema se encarrega de promover a exclusão que certamente vai gerar no seio da sociedade um nível de desigualdade quase que intransponível para aqueles menos favorecidos. Com esse entendimento, 


\section{artes de}

educar

ressaltamos que a escola pública carece de um tratamento capaz de garantir a oferta universal, gratuita e unitária de educação com qualidade, pois o que se observa nos sistemas de ensino atualmente é uma minoria dominante que estabelece aquilo que considera legítimo para a sociedade promovendo os status sociais que servem somete para perpetuar as desigualdades entre os povos.

Quando se traz à tona a questão da importância da equidade, é fundamental considerar que a qualidade na educação deve ser no sentido de garantir o direito de inclusão de todos os cidadãos na sociedade em rede, atentando para as questões não só do conhecimento, mas principalmente do crescimento pessoal do sujeito que atua e transforma o seu próprio contexto. Na busca por uma igualdade entre as pessoas e a garantia desses direitos, Tenti Fanfani (2008) esclarece no sentido de que

[...] o conhecimento das condições sociais emergentes deveria permitir evitar dois erros opostos. O primeiro é a educação como adaptação. De acordo com certos sujeitos, a melhor resposta da escola é a simples "adaptação" às características sociais dos alunos. Isto é o que muitas vezes ocorre quando as instituições acabam se mimetizando com a origem social dos alunos ("escolas pobres para os pobres", "escolas ricas para os ricos"). Por sua vez, tampouco tem que se cair na tentação de insistir com velhas receitas homogêneas que permitem o êxito escolar para alguns poucos e o fracasso para as maiorias (FANFANI, 2008, p. 2).

Considerando o posicionamento assumido pelo autor, apreendemos que se o sistema educacional tratar igualmente a sua clientela, certamente essa postura reforçará mais a desigualdade.Isso porque aqueles que dispõem de mais condições, sejam elas culturais, sociais ou econômicas, certamente continuarão sendo maiores beneficiários do capital cultural relacionados à construção dos saberes. Portanto, se a escola trata seus alunos de forma igual, ela certamente estará contribuindo para que questões específicas de desigualdade sejam postas em destaque. Essas impressões servirão como pano de fundo para trazer nessa discussão o contexto imposto pela pandemia ao sistema de educação no país.

\section{PANDEMIA NO BRASIL E SEUS IMPACTOS NA EDUCAÇÃO BÁSICA}

Os estudos sobre a pandemia no Brasil, no mundo, e seus impactos no contexto educativo, têm realçado discussões reflexivas e críticas sobre o papel e a função da escola no processo de ensino e aprendizagem, bem como da universidade no desenvolvimento de suas funções formativas. Boaventura de Sousa Santos (2020), em seu livro A cruel pedagogia do 
vírus, faz uma discussão relevante sobre o atual momento, descrevendo que "existe um debate nas ciências sociais sobre se a verdade e a qualidade das instituições de uma dada sociedade se conhecem melhor em situações de normalidade, de funcionamento corrente, ou em situações excepcionais, de crise"(SANTOS, 2020, p. 5).

De certo modo, podemos dizer que em nosso país, na atual conjuntura, o que observamos são instituições educativas com potencial desenvolvimento da ciência, da pesquisa e da extensão, promovendo intervenções positivas na formação de profissionais para atuarem nos diversos campos do conhecimento. Todavia, se analisarmos por outro viés dos investimentos na estrutura física, na formação de professores, inclusive voltados para as tecnologias da educação, na garantia de políticas públicas e na diminuição das desigualdades sociais, veremos que ainda estamos em passos lentos.

O documento Todos Pela Educação, entidade fundada em 2006 e reconhecida como uma organização da sociedade civil, independente, sem fins lucrativos, plural e suprapartidária, vem contribuindo em seus estudos e orientações normativas para a melhoria da Educação Básica no Brasil. A mesma apresentou a sua primeira nota técnica em abril de 2020, sobre o Ensino a distância na Educação Básica frente à pandemia do COVID-19, destacando que:

Em todo o território nacional, redes públicas e privadas interromperam o funcionamento das escolas e, entre outras ações, têm cogitado - ou já estão em processo de - transferir aulas e outras atividades pedagógicas para formatos a distância. Por ora, são as redes estaduais que mais têm avançado nesse sentido, e o caminho tem sido viabilizado, principalmente, por meio da disponibilização de plataformas online, aulas ao vivo em redes sociais e envio de materiais digitais aos alunos, como mostra recente levantamento realizado com mais de três mil Secretarias de Educação de todo o País. (NOTA TÉCNICA, TODOS PELA EDUCAÇÃO, 2020, p.3)

A nota técnica apresenta reflexões sobre as ações realizadas pelas Secretarias de Educação do país que, na sua maioria, realizam atividades educacionais remotas viabilizando o acesso ao ensino em tempos de pandemia. Deixa claro que são muitos os desafios e limitações do ensino remoto, sendo necessário o desenvolvimento de estratégias educacionais propositivas para uma tomada de decisão que favoreça um ensino de qualidade, de modo a minimizar as sequelas educativas no atual cenário.

As pesquisas do Centro de Inovação para a Educação Brasileira-CIEB (2020) em relação ao Planejamento das Secretarias de Educação do Brasil para Ensino Remoto apontam que as estratégias das redes estaduais de ensino até o momento que se destacam são: as 
plataformas online, vídeo-aulas gravadas (redes sociais), materiais digitais via redes, aulas online ao vivo (multisseriadas), aulas via TV, aulas online ao vivo (etapa específica), orientações genéricas via redes sociais, tutoriais/chat online.

As estratégias das redes municipais de ensino que ficaram mais evidentes nas pesquisas do CIEB (2020) foram: os materiais digitais (via redes), orientações genéricas via redes sociais, videoaulas gravadas (redes sociais), plataformas online e disponibilização de material impresso. Estas estratégias aparecem sutilmente nas pesquisas em relação ao número de municípios em todo o território brasileiro.

Nesse contexto, a nota técnica apresenta ainda quatro mensagens apoiadas em dados de pesquisas científicas com o intuito de fornecer pressupostos para a possíveis tomadas de decisões de gestores e profissionais da Educação Básica e assim define:

1- Frente ao atual momento, soluções de ensino remoto podem contribuir e devem ser implementadas. Mas, considerando seu efeito limitado, é preciso cuidadosa normatização e, desde já, atenção ao planejamento de volta às aulas.

2- Uma estratégia consistente para o ensino remoto é aquela que busca mitigar as condições heterogêneas de acesso e os diferentes efeitos de soluções a distância em função do desempenho prévio dos estudantes.

3- Ensino remoto não é sinônimo de aula online. Há diferentes maneiras de estimular a aprendizagem a distância e, se bem estruturadas, atividades educacionais podem cumprir mais do que uma função puramente acadêmica. 4- Mesmo à distância, atuação dos professores é central. (NOTA TÉCNICA, TODOS PELA EDUCAÇÃO, 2020, p.3).

Considerando as quatro mensagens descritas no documento da nota técnica do Todos pela Educação, podemos dizer que as escolas têm um grande desafio nesse processo de distanciamento social provocado pela pandemia, desde o mapeamento de acesso à internet, disponibilidade de recursos tecnológicos de alunos e professores, normatizações mediadas pelos sistemas de educação ao planejamento das ações educativas remotas de maneira reflexiva, atenta e cautelosa.

O enfrentamento a essas medidas de isolamento requer da escola e da Universidade mudanças significativas em suas práticas pedagógicas de ensinar pelos professores e gestores e principalmente dos alunos e familiares. As desigualdades sociais se tornam mais nítidas se levarmos em consideração os contextos socioculturais em nosso país. Portanto, é imprescindível (re)pensar as estratégias de ensino remoto, mas que estas não se resumam ao processo formativo de crianças, jovens e adultos. 
artes de

educar

Dessa maneira, o diálogo deve ser permanente, ativo, reflexivo e crítico com a intencionalidade de igualdade, equidade e universalização do ensino, não permitindo ações que excluam os protagonistas desse processo: os alunos - por isso a importância de propor atividades de aprendizagens que atendam a todos de modo plural, ético e comprometido. A organização e definição dessas ações devem ser formalizadas no coletivo, excluindo a ideia de benefícios empresariais, marqueteiros e políticos, mas com viés democrático e cauteloso considerando desde os aspectos administrativos - escolas na área urbana, rural, comunidades indígenas, tradicionais, quilombolas, pescadores - como o multiculturalismo presente nesses territórios.

Pensar nas estratégias de ensino à distância é centrar as atenções no saber fazer pedagógico de professorese de todos os envolvidos no processo educativo, com o olhar sistêmico para os contextos social, cultural e econômico em que a escola está inserida. É perceber que o Brasil, um país de grandes dimensões territoriais, enfrenta dificuldades de acesso à internet e às ferramentas tecnológicas necessárias para um bom desempenho de atividades remotas. Implica refletir sobre a formação de professores quanto ao uso das novas tecnologias da educação e principalmente das estruturas físicas das escolas, em grande parte pela ausência de investimento do poder público. É perceptível que este momento de pandemia trouxe à tona a realidade do nosso país tanto no contexto educacional, como também em relação ao nosso Sistema Único de Saúde.

O ensino remoto tem suas limitações e não conseguirá substituir a experiência escolar presencial, principalmente na educação básica, na qual a relação ensino-aprendizagem é permeada pelas interações sociais, dinamizadas pela construção coletiva do saber. As atividades remotas são essenciais no contexto atual em tempos de pandemia.No entanto, é importante que estas sejam desencadeadas com fim pedagógico, oportunizando conexão entre o virtual e as atividades presenciais.

Dessa forma, é preciso ter expectativas realistas quanto às diversas atividades remotas existentes, sabendo que elas são importantes alternativas no atual momento, mas não suprirão todas as necessidades acadêmicas esperadas e previstas nos currículos. A normatização das atividades remotas pelos Conselhos de Educação das três esferas, com base na Medida Provisória (MP) no 934, de 2020, que estabelece normas excepcionais sobre o ano letivo da educação básica e do ensino superior decorrentes das medidas para enfrentamento da situação de emergência de saúde pública de que trata a Lei n ${ }^{\circ}$ 13.979, de 6 de fevereiro de 2020 é outro ponto de destaque no documento da Nota Técnica, Todos Pela Educação. A MP nº 934, de 2020 aborda a flexibilidade do cumprimento dos 200 dias letivos, mantendo a carga horária 


\section{artes de}

educar

mínima anual conforme as orientações da Lei de Diretrizes e Bases da Educação (LDB). É importante afirmarmos a relevância das normas e diretrizes para essas atividades a distância com objetivos e fins pedagógicos, orientando os sistemas de ensino com as respectivas estratégias necessárias para o cenário em que se encontra a comunidade escolar.

As ações direcionadas ao processo educativo devem ser pensadas tanto no contexto atual da pandemia, bem como em outras situações futuras, repensando o trabalho da gestão administrativa e pedagógica em consonância com as orientações do sistema de ensino, estabelecendo planejamento e organização didático-pedagógica considerando as questões emocionais, sociais, culturais e econômicas. A receptividade no acolhimento de crianças, jovens e adultos no contexto da educação básica e o apoio familiar numa relação de parceria devem ser fortalecidas a cada dia para que juntos consigam enfrentar as intempéries provocados pela pandemia daCOVID-19.

Acreditamos que os desafios da educação brasileira no atual contexto pandêmico apontam para dois momentos distintos e que são complementares: a (re)estruturação didática pedagógica da relação ensino-aprendizagem e a busca de alternativas que auxiliem a manutençãoda sanidade mental da família, alunos e professores diante do isolamento social, com perspectivas de um trabalho que vise inicialmente acolher esses sentimentos que são complementares de insegurançaemedoe transformá-los em perseverança, otimismo, união e outros valores de fortalecimento de vínculos.

\section{REFLEXÕES E DESAFIOS EM TEMPOS DE PANDEMIA: na educação superior é diferente?}

Considerando que o ato de aprender não pode ser determinado de forma unívoca e, por isso, nem sempre as aprendizagens sugerem o estabelecimento de rupturas, quer com os saberes que possuímos, quer com os quadros gnosiológicos que utilizamos para atribuir significados e sentidos aos acontecimentos de natureza diversa que ocorrem no mundo no qual estamos inseridos (CHARLOT, 2000), há que reconhecer que, em determinados momentos e situações, a probabilidade de alguém aprender depende da possibilidade de se estabelecerem essas rupturas.

Nessa perspectiva, torna-se relevante compreender o significado de cotidiano como parte do dia a dia do sujeito em contextos variados e que muitas vezes se constituem em hábitos ou rituais. Para melhor apreensão, buscamos apoio nos escritos de Michel de Certeau (2008), quando afirma que "O cotidiano é aquilo que nos é dado cada dia (ou que nos cabe em 


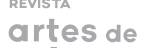

educar

partilha), nos posiciona dia após dia, nos oprime, pois existe uma opressão no presente. [...] o cotidiano é aquilo que nos prende intimamente a partir do interior. [...] o que interessa ao cotidiano é o invisível. (CERTEAU, 2008, p. 31).

Corroborando com o pensamento do autor, ressaltamos que é esse cotidiano que difere os sujeitos, seja pela condição econômica, social e principalmente cultural.Certeau (2008, p. 142) considera que toda atividade humana pode ser cultura, mas ela não o é necessariamente, ou, não é forçosamente reconhecida como tal, pois "para que haja cultura, não basta ser autor das práticas sociais; é preciso que essas práticas sociais tenham significado para aquele que as realiza" (CERTEAU, 2008, p. 142).

Partindo da necessidade e importância de se considerar o cotidiano presente na universidade brasileira, não devemos camuflar as condições hoje vividas pelos que fazem essa instituição, principalmente se partimos da ideia de universidade como um espaço de vida, troca de experiências e, por excelência, de construção do conhecimento. Apesar das dificuldades impostas pelas tecnologias, é temeroso afirmar que as atividades remotas sejam consideradas satisfatórias. No entanto, temos que argumentar no sentido de que o ideal seria que todo profissional docente, independente do nível em que atua, estivesse preparado para fazer uso de todas as ferramentas e recursos que hoje ainda são, em boa parte, específicos para a educação a distância.

Não só a Universidade, mas também a escola básica, precisa de maior atenção no sentido de disponibilizar recursos conforme a sua realidade e seu contexto político e regional, considerando que os professores também carecem de atualização tanto pedagógica quanto tecnológica, pois a partir das suas experiências e vivências serão capazes atender as especificidades dos seus estudantes com relação às diferentes demandas que se impõem. Assim, diante desse quadro é fundamental fazer uso das tecnologias e, mesmo tendo a convicção de que muito pouco está sendo feito, é possível garantir um mínimo de normalidade no estágio atual de pandemia que assola o país, até porque há um misto de insegurança e de incerteza quanto aos rumos da universidade pública.

\section{ATIVIDADES CURRICULARES EM CONTEXTOS DIVERSIFICADOS}

O estado do Amazonas - AM tem uma população estimada em 4.144.597 milhões de habitantes, de acordo com os dados do Instituto Brasileiro de Geografia e Estatística - IBGE (2019). É o maior estado do Brasil, com a maior floresta tropical do mundo, localizado ao norte, tendo como capital Manaus. Limita-se ao norte com a Venezuela e o estado de 
Roraima; a leste com o estado do Pará; a noroeste com a Colômbia; a sudeste com o Mato Grosso; a sudoeste com o Peru e o estado do Acre e ao Sul com o estado de Rondônia.

Para José Camilo Ramos de Souza (2013) o estado do Amazonas é um "lugar de múltiplos fenômenos físicos e sociais, bastante complexo"(SOUZA, 2013, p. 21). É essa complexidade que deve ser considerada na atual conjuntura de pandemia, em relação às questões educacionais. O olhar deve estar voltado para o planejamento de estratégias e ações, definidas e organizadas com base nas normativas estabelecidas pelos sistemas de ensino, considerando toda pluralidade e diversidade de populações presentes no território.

Nessa perspectiva, a Universidade Federal do Amazonas - UFAM, por meio da Próreitora de Ensino e Graduação - PROEG, publicou a Portaria nº 31, de 30 de abril de 2020, e a de $\mathrm{n}^{\mathrm{o}} 36$, de 8 de maio de 2020. Estes documentos versam sobre as possibilidades de realização de Atividades Extracurriculares Especiais-AEE, em caráter excepcional, por meio de ferramentas de Tecnologias de Informação e Comunicação (TICS), no contexto da UFAM, durante a suspensão das atividades administrativas presenciais, bem como das atividades acadêmicas da graduação, presenciais ou não presenciais, enquanto durar o período de combate à pandemia do Coronavírus.

A Portaria deixa bem claro que as AEEs devem ser validadas pela coordenação, correspondendo a ações formativas de ensino, pesquisa e extensão na graduação. Esclarece em seu artigo $3^{\circ}$ que essas atividades têm por objetivos o enriquecimento científico, técnico, tecnológico, cultural, aprofundamento e/ou atualização de conhecimentos específicos que complementam a formação acadêmica, especialmente durante o período de suspensão das atividades regulares por força da pandemia da COVID-19.

Assim, intencionamos dizer que o documento, que permite a realização das Atividades Extracurriculares Especiais - AEE, traz uma orientação sistemática de como realizá-las. No entanto, se torna necessária uma discussão aprofundada sobre os mecanismos de acompanhamento e/ou orientação pedagógica, garantindo uma avaliação dessas ações didático-metodológicas que serão ofertadas de forma remota, favorecendo reflexões sobre os processos de ensino-aprendizagem, considerando as condições estruturais, culturais, sociais e econômicas de professores, alunos e principalmente da universidade.

A Portaria estabelece ainda os recursos e/ou meios para a oferta das AEEs, definindo em seu art. $5^{\circ}$ que estas Atividades Extracurriculares Especiaisdeverão ser planejadas e ofertadas por meio de ferramentas de TICS, preferencialmente dentro da plataforma Google, onde o docente deve possuir uma conta institucional vinculada, via email, ou ainda, pela plataforma institucional Moodle, especificando assim, por meio do 
parágrafo único que "o docente, a seu critério e mediante avaliação quanto à adequabilidade para a realização da AEE específica, poderá utilizar outros recursos de mídia digital e ferramentas disponíveis em redes sociais, ou quaisquer outras plataformas" ( PROEG/UFAM, Portaria de $\mathrm{n}^{\circ} 36$, de 30 de maio de 2020).

Apesar de todas essas possibilidades, a Portaria não permite o aproveitamento dessas atividades como disciplinas optativas e/ou obrigatórias, seja de forma parcial ou total, apenas como Atividades Acadêmicas Curriculares Complementares - AACC. Nessa perspectiva, estabelecemos um diálogo sobre a atuação dos campi do interior da Universidade Federal do Amazonas - UFAM em relação à pandemia do Coronavírus com o propósito de discutir sobre as atividades remotas, bem como provocar reflexões referentes ao retorno do trabalho docente no contexto da IES, promovendo uma articulação com base nos dados internos e considerando os pressupostos teóricos que fundamentam os diálogos, a fim de contribuir para registros e debates futuros.

Dessa maneira, realizamos uma análise da pesquisa de monitoramento da COVID19dos acadêmicos do campus do interior, que objetivou apresentar um panorama sobre os discentes em relação às questões relacionadas ao período de pandemia, com informações autodeclaradas. As informações obtidas por meio desses resultadosauxiliam às demais comissões e subcomissões na elaboração de metas e ações educativas que serão desenvolvidasdurante o período de isolamento social e o retorno das atividades presenciais nos campi do interior da Universidade Federal do Amazonas - UFAM de forma segura e atendendo as exigências da Organização Mundial de Saúde - OMS.

Participaram dossubcomitês de enfrentamento à COVID-19dos interiores da UFAM na produção desses dados o Instituto de Ciências Sociais, Educação e ZootecniaICSEZ/PARINTINS, Instituto de Saúde e Biotecnologia-ISB/COARI, Instituto de Ciências Exatas e Tecnologia ICET/ITACOATIARA, Instituto de Natureza e Cultura- INC/ BENJAMIN CONSTANT e Instituto de Educação, Agricultura e Ambiente IEAA/HUMAITÁ.

As discussões e reflexões terão como base os resultados da pesquisa realizada pelos subcomitês de enfrentamento das unidades do interior da UFAM, no período de 25 a 30 de maio de 2020, que contou com a participação de 1.117 discentes de forma voluntária, autodeclarada, tendo como instrumento o formulário online divulgado virtualmente pelo WhatsApp, contendo questões simples, a fim de obter dados sobre a situação dos discentes em relação à COVID-19, conforme a Figura 1, a seguir. 
Figura 1: Dados Gerais de participantes da pesquisa: respondentes por campus e município.

\section{Dados Gerais}
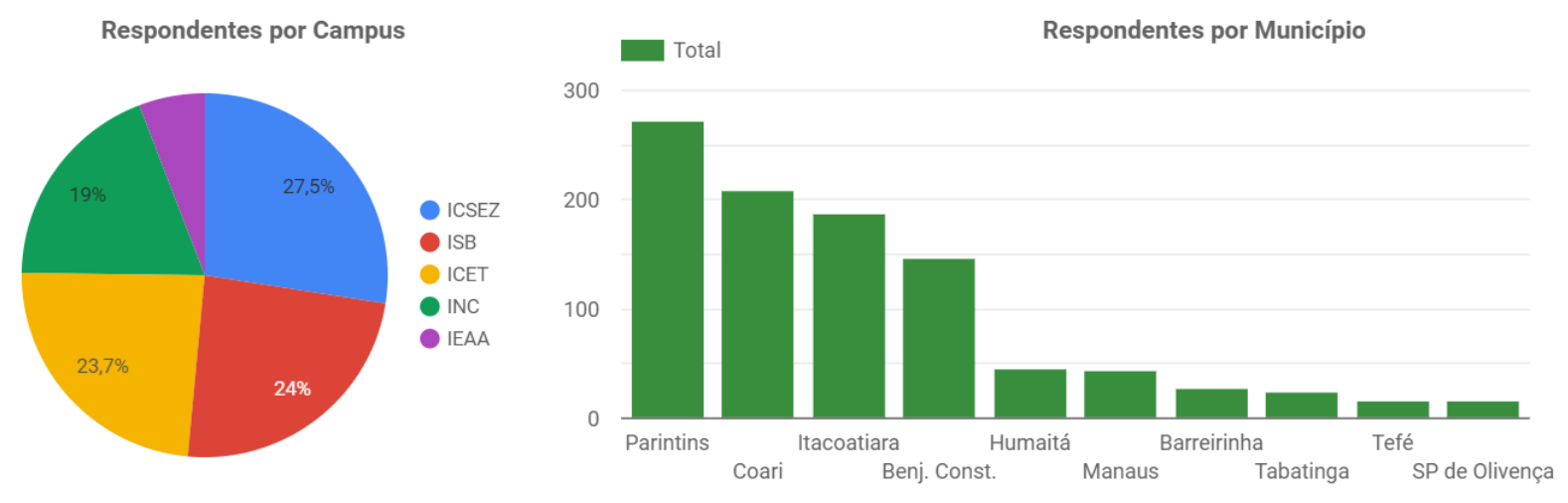

Fonte: Subcomitê de Combate ao COVID-19 das unidades do interior da Universidade Federal do Amazonas (2020). Disponível em: https://datastudio.google.com/u/0/reporting/d0802ebd-62a9-428c-89d8 c2a6989f2aacc/page/6zXD.

Considerando a devolutiva por campus, tivemos uma participação de 5,8\% de discentes do Instituto de Educação, Agricultura e Ambiente IEAA/HUMAITÁ, 19\%Instituto de Natureza e Cultura- INC/ BENJAMIN CONSTANT, 23,7\% do Instituto de Ciências e Tecnologia - ICET/ITACOATIARA, 24\% do Instituto de Saúde e Biotecnologia-ISB/COARI e $27,5 \%$ Instituto de Ciências Sociais, Educação e Zootecnia- ICSEZ/PARINTINS destacando os respondentes por município no qual se localizam os campi.

Essas informações permitem dizer que os campi do interior possuem discentes de diversas cidades e com distância bem expressivas entre elas. Por exemplo, a cidade de SP de Olivença que dista aproximadamente $1.377 \mathrm{~km}$ da cidade de Parintins. Destacamos esse limite territorial por compreendermos que esses aspectos, relacionados ao local de habitação dos discentes, contribuem para a análise no momento de planejar e definir as atividades remotas na universidade.

Os estudos de Turra, Encone e Santánna (1975) realçam a necessidade de conhecer a realidade local de habitação e moradia de alunos no contexto educativo, favorecendo olhares múltiplos. Ou seja, "é essencial que o professor efetue um balanço sistemático das características, condições e problemas da realidade em que vai atuar" (TURRA, ENCONE e SANTÁNNA, 1975, p.28). É preciso analisar as diferentes realidades dos alunos das universidades sempre, e em especial nesse momento de pandemia, quando essas questões se tornam mais próximas e evidentes, exigindo não só da academia, mas principalmente do professor, um cuidado mais acurado no sentido de alcançar um universo maior de atendimento, considerando o leque de dificuldades enfrentadas por esses alunos. 
Assim, o acesso à internet e demais recursos tecnológicos são importantes, no entanto é fundamental considerar se existe a equidade no momento do acesso a essas ferramentas, permitindo desta forma que não se gere mais uma situação que acentue a desigualdade socioeducativa no contexto regional. Dessa forma, o planejamento didático pedagógico consciente e reflexivo, na perspectiva de Turra, Encone e Santánna (1975), “deve ser elaborado em função das necessidades e das realidades apresentadas pelos alunos"(TURRA, ENCONE e SANTÁNNA, 1975, p.28). Vale salientar que dados como os apresentados na Figura 2 são importantes para que se possa traçar ações relevantes para as demandas apresentadas.

Figura 2: Dados Gerais de participantes da pesquisa: respondentes por Gênero/Campus, e por Cor/Etnia Autodeclarada por Campus
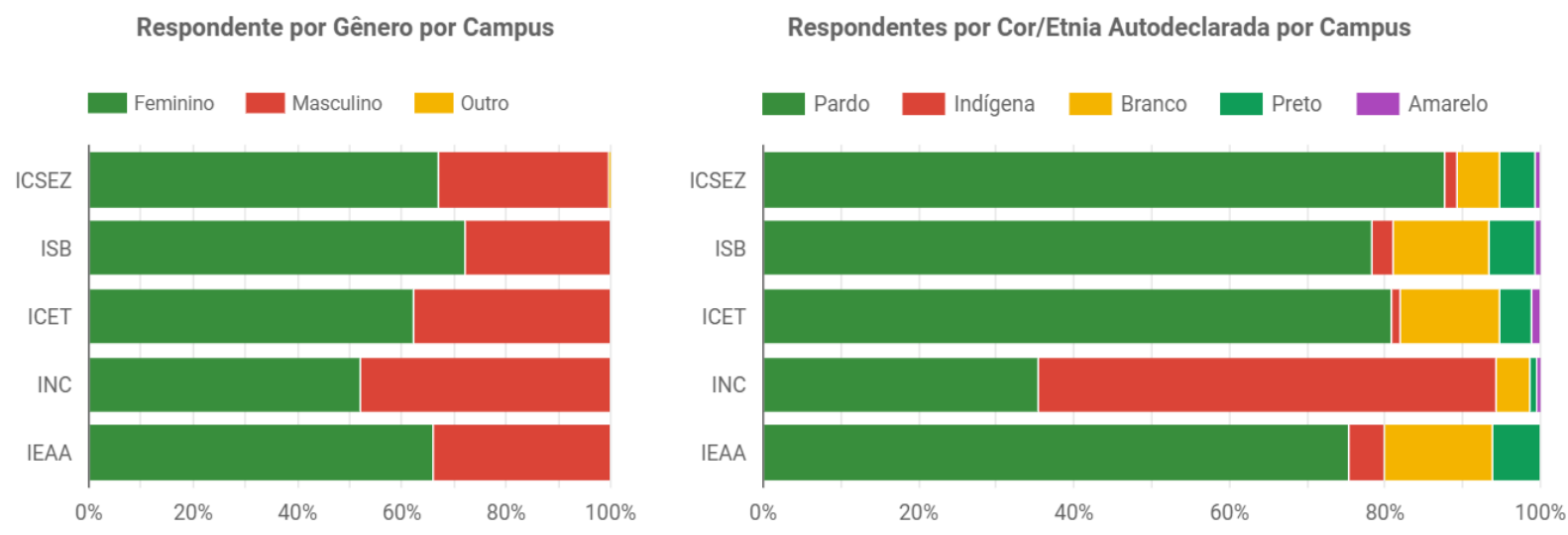

Fonte: Subcomitê de Combate ao COVID-19 das unidades do interior da Universidade Federal do Amazonas (2020). Disponível em: https://datastudio.google.com/u/0/reporting/d0802ebd-62a9-428c-89d8 c2a6989f2aacc/page/6zXD.

Em relação aos dados gerais da pesquisa, quanto às questões de gênero/campus e por cor/etnia autodeclarados, observamos em todos os campi que o maior número de respondentes foi do gênero feminino. Em relação a cor/etnia, identificamos como predominante a autodeclaração de pardo(a) na maioria dos campi do interior, com destaque para o campus do Instituto de Natureza e Cultura- INC/ BENJAMIN CONSTANT que tem em sua maioria 


\section{artes de}

educar

indígenas. A identificação de cor/etnia branco, preto e amarelo apresenta menor porcentagem entre os campus.

O reconhecimento do perfil populacional dos discentes em relação cor/etnia é relevante para situarmos o desenvolvimento de atividades remotas em período de isolamento social, bem como a estruturação das ferramentas didático-metodológicas, permitindo aos docentes a sua compreensão dos contextos sócio-históricos-antropológicos de cada discente. Para Carvalho (2002), "pensar em respostas educativas da escola é pensar em sua responsabilidade para garantir o processo de aprendizagem para todos os alunos, respeitandoos em suas múltiplas diferenças"(CARVALHO, 2002, p. 70).

É oportuno destacar que o trabalho docente, nessa perspectiva, deve atender às singularidades étnicas culturais, respeitando as crenças, modos e concepções de viver. Com base nessa compreensão, observamos que o monitoramento realizadopresentou os perfis dos alunos ressaltando a importância de conhecer quem são os protagonistas na universidade, permitindo, ainda, o despertar para "[...] uma série de desafios, alguns inéditos, que precisam ser assumidos e incorporados na prática docente. A mudança, o novo, o questionamento, o diferente, quase sempre são causa de insegurança e medo. Mas é necessário ousar e enfrentar" (HEERDT;COPPI2003, p. 70).

Os desafios que surgem no atual cenário estão relacionados ao desenvolvimento da prática pedagógica com suas inovações didático-metodológicas, com mudanças significativas quanto a inserção de ferramentas tecnológicas para o processo de ensino e aprendizagem nas atividades remotas e/ou ensino híbrido. Contudo, a pesquisa sobre o monitoramento da COVID-19 realizada com os discentes evidenciou, além das informações relacionadas ao gênero, cor/etnia autodeclarada por cursos, nas unidades existentes em cada campus do interior, o cruzamento das informações de gênero e cor/raça (autodeclarada) versus pertencer ao grupo de risco e de discentes infectados pelo Coronavírus conforme a Figura 3.

Figura 3:Respondentes por Gênero, cor/etnia, pertencentes ao Grupo de Risco e representatividades dos discentes com COVID-19 


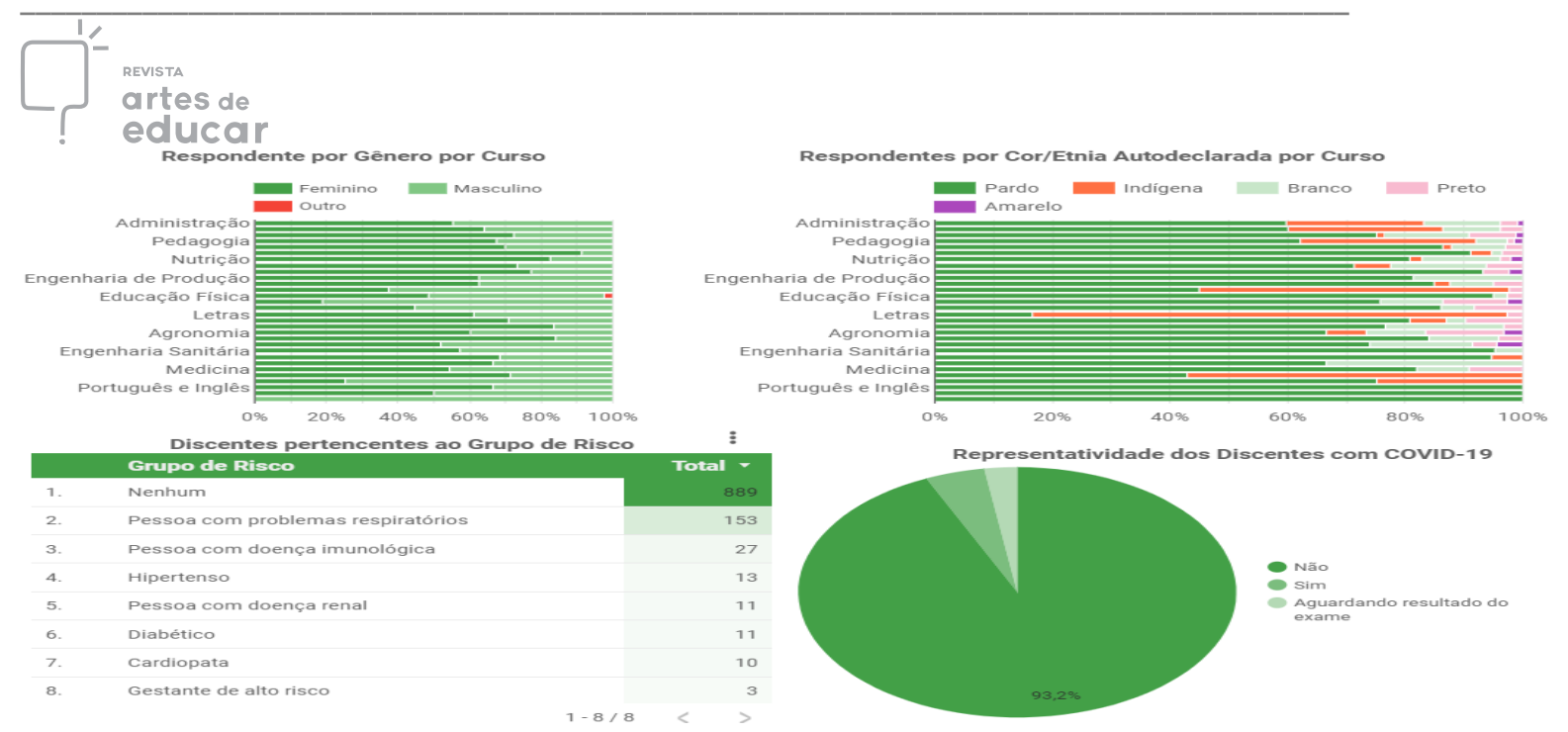

Fonte: Subcomitê de Combate ao COVID-19 das unidades do interior da Universidade Federal do Amazonas (2020). Disponível em: https://datastudio.google.com/u/0/reporting/d0802ebd-62a9-428c-89d8 c2a6989f2aacc/page/6zXD.

Em relação aos informantes ${ }^{\mathrm{v}}$ por curso, os resultados demonstram que o gênero feminino tem sua maioria nos cursos dos Institutos, enquanto que o gênero masculino teve sua maior parcela de participação nos cursos de Ciências Agrárias e Engenharia de Software, com destaque para o curso de Educação Física que teve igualdade de participação entre os gêneros feminino e masculino, com participação de outros gêneros.

Sobre os discentes que responderam à pesquisa por cor/etnia autodeclaradas, percebemos que a maioriase autodeclara pardo. Os informantes dos cursos de Ciências Agrárias, Letras e Antropologia são indígenas autodeclarados. As cores/etnias branco, preto e amarelo tiveram uma participação pequenanesse processo de monitoramento.

Os dados evidenciam, ainda, que dos 1.117 discentes que participaram da pesquisa, 885 não fazem parte do grupo de risco, 153 tem problemas respiratórios, 27 apresentam doenças imunológicas, 13 são hipertensas, 11 possuem problemas renais, 11 são diabéticos, 10 são cardiopatas e 3 são gestantes. Dessa maneira, os resultados da pesquisa trazem como representatividades dos discentes com COVID-19, nos campi da UFAM do interior, os seguintes dados: 93,2\% até a análise dos resultados não apresentaram sintomas do Coronavírus, $4,4 \%$ foram diagnosticados com o vírus e $2,4 \%$ aguardam os resultados dos exames.

De posse dessas informações, apresentamos a seguir diálogos reflexivos sobre os resultados da pesquisa realizada com os discentes do Instituto de Ciências Exatas e Tecnologia - ICET/UFAM, localizado a $269 \mathrm{~km}$ aproximadamente da capital do Amazonas, Manaus. O Instituto conta com nove cursos de graduação: Agronomia, Engenharia de Software, Engenharia de Produção, Engenharia Sanitária, Farmácia, Química Industrial, 
educair

Sistema de Informação, Licenciatura em Ciências: Química e Biologia e, Licenciatura em Ciências: Matemática e Física.

É importante ressaltar que o Instituto conta com o Programa de Pós-Graduação em Ciência e Tecnologia para Recursos Amazônicos, em nível de mestrado, com identidade multidisciplinar, com destaque para as seguintes linhas de pesquisa: Agrobioenergia;Análise e manejo de recursos amazônicos; Prospecção química, biológica e desenvolvimento de substâncias bioativas e Recursos amazônicos e desenvolvimento socioambiental.

A escolha de dialogar reflexivamente sobre o contexto da educação em tempos de pandemia nos/dos campi do interior da Universidade Federal do Amazonas - UFAM, tendo como recorte a pesquisa realizada pelo ICET, se justifica pelo fato dessa instituição ser o campo de atuação de um dos autores deste estudo. É importante ilustrar que o Instituto de Ciências Exatas e Tecnologia - ICET tem 2.085 alunos. Deste total, 1.280 se matricularam para o período de 2020.1 e 805 não efetivaram matrícula. A seguir apresentamos os dados da pesquisa realizada com 414 discentes do Instituto de Ciências e Tecnologias-ICET/UFAM, por meio da ferramenta do Formulário Google, divulgada nos grupos de WhatsApp dos cursos de graduação. Apresentamos esses dados, destacando: oscursos, local de moradia, município atual, opinião sobre atividades didáticas remotas, tipo de acesso, acesso à internet $\mathrm{e}$ qualidade da internet.

Figura 4: Dados da pesquisa realizados com os discentes do Instituto de Ciências e TecnologiasICET/UFAM- Cursos, local de moradia, município atual, opinião sobre atividades didáticas remotas, tipo de acesso, acesso à internet e qualidade da internet

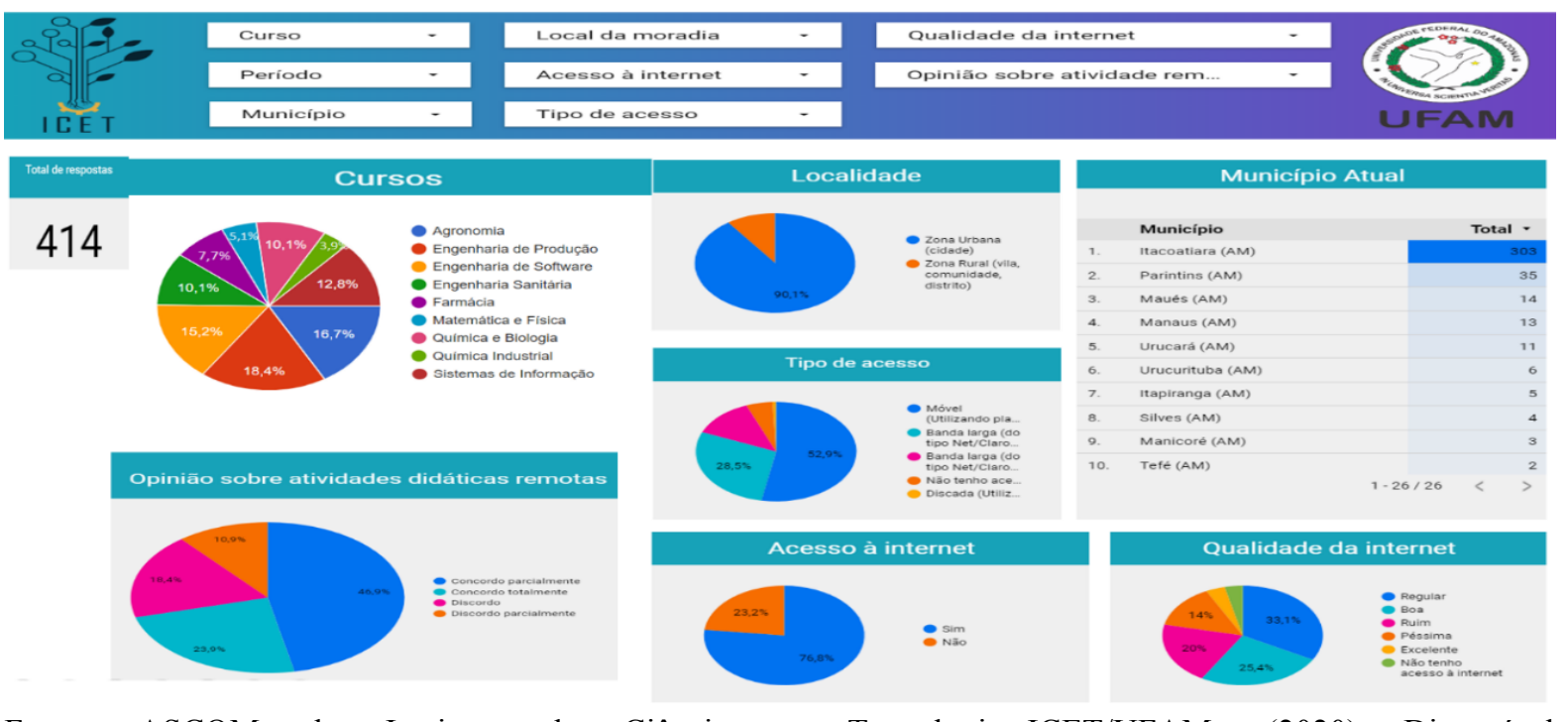

Fonte: ASCOM do Instituto de Ciências e Tecnologias-ICET/UFAM. (2020) Disponível: https://datastudio.google.com/reporting/1g7C5h9NCjF49xapkyV5kVYx51dq9NSI3/page/XbIRB. 
Participaram dessa pesquisa como respondentes discentes dos nove cursos do Instituto de Ciências Exatas e Tecnologia - ICET: 16,7\% do curso de Agronomia, 15,2\% do curso de Engenharia de Software e 18,4\% de estudantes de Engenharia de Produção. Do curso de Engenharia Sanitária, 10,1\% responderam ao formulário, 7,7\% de Farmácia, 3,9\% de Química Industrial e 12,8\% do curso de Sistemas de Informação. As Licenciaturas em Ciências: Química e Biologia e Licenciatura em Ciências: Matemática e Física tiveram pouca participação nas respostas do formulário com 10,1\%-Q/B e 5,1\%-M/F.

Os dados analisados apresentam os cursos de Engenharia de Produção, Agronomia e Engenharia de Software com maior participação de respondentes, e esses residem em sua maioria na zona urbana (90,1\%). Os munícipios dos discentes respondentes são: ItacoatiaraAM (303), Parintins-AM (35), Maués-AM (14), Manaus-AM (13), Urucará-AM (11), Urucurituba-AM (06), Itapiranga-AM (05), Silves-AM (4), Manicoré-AM (3) e Tefé-AM (2). As cidades de Barreira-AM (02), Boa Vista do Ramos- AM (02), Coari- AM (01), TabatingaAM (01), Porto Velho- RO (01), Várzea Grande-MT (01), Humaitá- AM (01), Careiro da Várzea- AM (01), Oriximiná-PA (01), Iranduba- AM (01), São Sebastião do Uatumã- AM (01), Pauini- AM (01), Juruti-AM (01), São Paulo de Olivença-AM (01) e Alenquer-PA (01)foram citas pelos discentes do instituto, no entanto, não foram apresentadas na tabela.

Compreendemos, nesse contexto, que o fato de os discentes residirem na sua maior parte na zona urbana, inclusive no município sede do instituto, favorece uma melhor comunicação e relação entre a universidade e discentes. Nesse sentindo, é preciso observar o percentual de alunos na zona rural, que totaliza 41 alunos $(9,9 \%)$, aspecto esse que influenciará nas tomadas de decisões em relação ao ensino remoto durante o período de isolamento e distanciamento social.

Dessa forma, o tipo de acesso utilizando o plano de dados móvel (celular) chega a $52,9 \%$, demonstrando que mais da metade dos respondentes tem acesso à internet. $\mathrm{O}$ percentual de discentes que fazem uso da Banda larga (do tipo Net/Claro, Oi fibra, Oi Velox, Live Tim, Vivo Fibra) é de 28,5\%. Os que usam os dados móveis com plano de dados do celular por meio da banda larga (do tipo Net/Claro, Oi fibra, Oi Velox, Live Tim, Vivo Fibra) é $12,6 \%$. Foi verificado, ainda, que $0,7 \%$ utilizam a telefonia fixa discada e 5,3\% não têm acesso à internet.

Os resultados revelam que 76,8\% têm acesso à internet e 23,2\% não têm acesso. Em relação a qualidade da internet, 33,1\% consideram regular, 25,4\% boa, 20\% ruim, 14\% péssima, 3,9\% excelente e 3,6\% não têm acesso à internet. Em se tratando da opinião sobre as 
atividades didáticas remotas, os dados revelam que 46,9\% concordam parcialmente, $23,6 \%$ concordam totalmente, $18,4 \%$ discordam e $10,9 \%$ discordam parcialmente.

Partindo dos resultados do monitoramento dos discentes dos campi do interior da Universidade Federal do Amazonas, que mesmo tendo discentes com possibilidades de realizar atividades remotas durante o período de isolamento social, esse percentual não é uníssono. Partimos da concepção da educação democrática e igualitária, conforme expressa a Declaração Mundial sobre Educação para todos (1990), no seu Artigo 3º, quando esclarece que é necessário universalizar o acesso à educação e promover a equidade, melhorando sua qualidade, bem como tomar medidas efetivas para reduzir as desigualdades.

Tomando como base a declaração, ressaltamos a referência à universalização da educação e, em especial nesse momento de isolamento social, devemos buscar ações que garantam o direito dos alunos às suas aprendizagens, sem exclusão social, regional, cultural, étnica e econômica. A igualdade de condições de acesso ao ensino no atual contexto deve ser pensada de forma humana, respeitando a diversidade e os diferentes contextos dos alunos.

Garantir a permanência e o sucesso das ações para o atendimento cognitivo, emocional, cultural e social dos alunos universitários é um desafio que requer reflexões e diálogos permanentes com todas as áreas de ensino, pesquisa e extensão, considerando as diferentes realidades, conforme os resultados do monitoramento. Nessa perspectiva, a Figura 5 ressalta os dados da pesquisa realizada com os discentes do Instituto de Ciências Exatas e Tecnologias-ICET/UFAM em relação ao acesso a recursos para o desenvolvimento de atividades remotas.

Figura 5: Dados da pesquisa realizados com os discentes do Instituto de Ciências e Tecnologias ICET/UFAM - Acesso a Recursos para o desenvolvimento de atividades remotas 
Qual o tipo de equipamento você tem acesso? Escolha a(s) que mais se adeque $(\mathrm{m})$ : 414 respostas

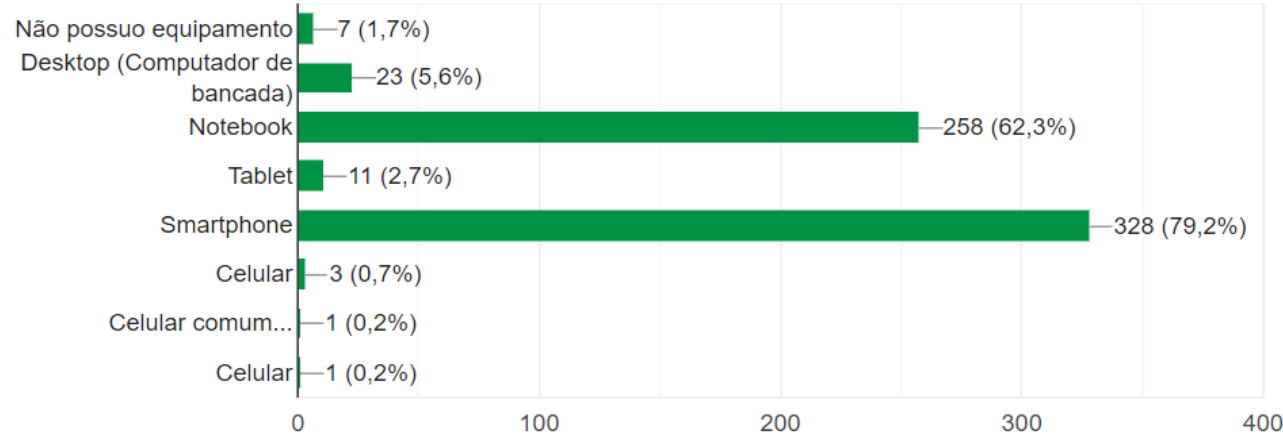

Fonte: ASCOM do Instituto de Ciências e Tecnologias-ICET/UFAM. (2020) Disponível: https://datastudio.google.com/reporting/1g7C5h9NCjF49xapkyV5kVYx51dq9NSI3/page/XbIRB.

Sobre o acesso a recursos para o desenvolvimento de atividades remotas, podemos dizer que do total de 414 respondentes do formulário da pesquisa, 328 possuem smartphone,representando $79,2 \%$ do total de participantes.Destes, sete não possuem equipamento (1,7\%). Foi citado por 23 discentes (5,6\%) que estes dispõemde desktop (computador de bancada)como recurso para a utilização em atividades remotas. Os notebooks, tablets e celulares também aparecem como recursos que os discentes podem utilizar nesse período de isolamento social.

Entre as diversas metodologias tecnológicas, destacamos o ensino híbrido, sinalizando diálogos em relação a essa estratégia, no atendimento às necessidades iniciais nas instituições educativas públicas, haja vista que a Educação Básica e principalmente as universidades estão se mobilizando por meio de seus comitês e subcomitês no planejamento de ações estratégicas que possam garantir aos alunos o direito de aprendizagem durante e após pandemia.

O ensino híbrido, de acordo com Valente (2015), é “[...] uma abordagem pedagógica que combina atividades presenciais e atividades realizadas por meio das tecnologias digitais de informação e comunicação (TDICs) [...]” (VALENTE, 2015, p. 17). Essa estratégia pedagógica pode auxiliar os espaços educativos na promoção do ensino, estabelecendo a relação entre online e/ou presencial, bem como off-line. A importância dos diálogos em caso da Educação Básica e das Universidades optarem pelo ensino híbrido se tornam relevantes principalmente na (re)elaboração de saberes pedagógicos, considerando o papel do professor e do aluno, a organização do espaço escolar, desde a avaliação de ensino, a culturae a gestão 
escolar, com reflexões permanentes e enriquecidas de estratégias didáticas pedagógicas que atendam as singularidades dos alunos e respeitem suas limitações de aprendizagem.

\section{CONSIDERAÇÕES FINAIS PARCIAIS}

Para o desenvolvimento deste artigo, buscamos conceitos como igualdade e equidade para inserir nas discussões em torno da educação no momento atual que o planeta enfrenta. Enfocamos a igualdade e a equidade como promotoras da justiça social com o intuito de descortinar a atual situação em que se encontram as instituições educacionais e as pessoas que dela fazem parte nesse contexto de pandemia provocada pela COVID-19. As limitações, medo, angústia e preocupações sobre o enfretamento da escola e da Universidade são desafios permanentes que se impõem no sentido de evidenciar a incapacidade do Estado no combate aos problemas que emergem por conta da crise sanitária no país.

Inúmeros elementos constituem esse quadro que, na verdade, se aglomeram em problemas muitas vezes operacionaisque dificultam ou até mesmo inviabilizam a implementação de um modelo de ensino que nunca foi parte efetiva do modelo que prevalece. Nesse sentido, convém destacar algumas situações que, na sua maioria, independem de condições técnicas.

Os resultados elencados enfatizam que os alunos em sua grande maioria possuem ferramentas tecnológicas e essas informações despertam reflexões críticas sobre o papel da Escola e da Universidade no Brasil, durante e pós-pandemia, requerendo debates sobre o desenvolvimento das atividades pedagógicas e formativas no contexto dos processos de formação.

Se de um lado os dados demonstraram a disponibilidade de ferramentas para que os alunos possam se beneficiar da aprendizagem oferecida de maneira remota, por outro é fundamental chamar a atenção para o fato de que só essa disponibilidade não é garantia de êxito, isso porque nesse universo não podemos ocultar, por exemplo, a qualidade da energia e consequentemente da internet na maioria dos municípios brasileiros; o alto índice de famílias que vivem em condições de extrema pobreza expressando a questão da desigualdade social e a falta de aparelhamento das Escolas e das Universidades com os recursos mínimos destinados aos estudantes.

Esses elementos são partes importantes das reflexões e diálogos que propomos neste estudo, principalmente em relação aos docentes, profissionais que estão na linha de frente da formação de pessoas para o seu desenvolvimento cognitivo, psicológico, cultural, social e 
afetivo. Dessa maneira, quando ponderamos sobre esses elementos, estamos buscando identificar outros que possam evidenciar a igualdade, a equidade no âmbito da escola e da academia.

Podemos dizer que esse momento de pandemia que o mundo e especificamente o Brasil está passando, trouxe um olhar reflexivo sobre como se encontram os sistemas de Saúde e, em especial, o de Educação, mostrando as realidades das estruturas físicas das instituições escolares, da formação de professores, dos recursos tecnológicos disponíveis e do seu funcionamento que ainda hoje são precários e que requerem investimentos do poder público e não cortes como vem ocorrendo atualmente.

As desigualdades sociais provocadas pela ausência de políticas públicas educacionais têm dificultado os avanços. Todas as ponderações refletem na tomada de decisões para o enfrentamento dos desafios não somente relacionados a pandemia provocada pelo Coronavírus, mas também a outros problemas que as instituições educativas têm em seu desenvolvimento pedagógico e que se unem às ações diretivas sobre o retorno das atividades docentes no atual cenário. Observa-se também uma ausência do Ministério da Educação em relação aos direcionamentos enquanto sistema. Mesmo sabendo que essas instituições educativas possuem autonomia, se espera uma diretriz em larga escala.

Dessa maneira, compreendemos que os docentes, independente do nível de ensino em que atuam, além de profissionais são pessoas que assumem papéis diversos em seu contexto de vida pessoal e nesse momento de isolamento social suas ações no convívio familiar ficam mais nítidas: os docentes são pais/mães, professores de seus filhos/filhas (no acompanhamento das atividades remotas). Sem esquecer que esses ainda têm atuado remotamente em suas atribuições nos espaços educativos por meio de reuniões em conselhos, colegiados, núcleos docentes estruturantes, gestão escolar e outras comissões relevantes para a organização e tomada de decisões nas instituições escolares.

A pressão exercida pelo governo sobre as instituições públicas de ensino é muito forte na tentativa de evidenciar que nesse período de isolamento é como se o professor estivesse em férias. Mas, na verdade, as ações pedagógicas de professores não estão relacionadas apenas ao ensino, mas a pesquisa, extensão e produção de saberes.

Muitos desconhecem que o trabalho do professor, na tentativa de facilitar por menor que seja a implementação de atividades remotas, é desgastante, visto que ele também tem as suas limitações quanto ao manejo dessas ferramentas e aquilo que chamamos de reinvenção passa pela clareza que o professor tem da sua prática e principalmente pela percepção que a universidade expressa dessa prática. 
É preciso considerar as diversidades culturais, sociais e principalmente econômicas em relação às diferentes situações em que se encontram os alunos e os professores. Assim, tornase importante estabelecer alianças entre os sistemas de ensino, universidade, escola, família e comunidade em geral, atentando para compreender o papel da escola e da universidade nas tomadas de decisões, considerando os contextos sócio-históricos local, regional e nacional.

Outro aspecto que consideramos importante ilustrar se refere às questões psicológicas de alunos, professores, pais e de toda a comunidade escolar, haja vista que as instituições escolares precisam estar organizadas para lidar com o medo, as angústias, o estresse e a depressão provocados pelo isolamento social, não podendo esquecer que todos precisam estar preparados para que este retorno aconteça com segurança, tanto nos aspectos físicosquanto psicológicos.

Vale ressaltar, ainda, que além dos problemas estruturais, pedagógicos, econômicos e sociais, as instituições educacionais devem pensar alternativas para lidar com a evasão escolar pela perda de motivação dos alunos com seu aprendizado, causada pelo afastamento do ambiente escolar e pelo menor engajamento com o ensino remoto, como também com a Síndrome de Estresse Pós-Traumático (SEPT): aumento da ansiedade e da agressividade, dificuldades de concentração e em casos mais graves maior incidência de insônia, depressão eaté mesmo suicídio. Essas e inúmeras situações adentram nos desafios educacionais.

Sem a pretensão de esgotar essa discussão, realçamos algumas propositivas com o intuito de contribuir na construção de mecanismos e/ou ações pedagógicas que auxiliem na reflexão das atividades remotas e/ou ensino híbrido, bem como outros direcionamentos relacionados a discussão em foco. Assim, damos ênfase à necessidade de elaboraçãode planos de estudos e de formação para apropriação dos conceitos relacionados às tecnologias aplicadas à educação, proporcionando debates sobre seus usos, os softwares disponíveis e sua aplicação no cotidiano da prática docente, bem como o acompanhamento pedagógico e da sistemática de avaliação das atividade propostas pelos docentes, seguido de atendimento psicológico e/ou terapêutico para docentes e alunos com atenção aos cuidados emocionais que a situação traz, proporcionando o cuidado da saúde emocional.

A elaboração de programas de recuperação de aprendizagem considerando o espaçotempo dos alunos deve ser considerada, como também o trabalho colaborativo entre universidade e escola, com diagnóstico da realidade escolar, reorganização do calendário, articulação com os Conselhos de Educação em suas esferas, elaboração de um plano de prevenção para os possíveis desafios que emergem em torno do campo educativo, favorecendo uma prévia das dificuldades que porventura surjam, estabelecendo uma relação 


\section{artes de}

educar

coletiva nos diversos campos do conhecimento de maneira multidisciplinar, especialmente da saúde e da Assistência Social, e principalmente a formação docente com o objetivo de orientar e dinamizar as práticas em EAD, com o ensino híbrido como proposta para as atividades remotas, de acordo com o cumprimento dos protocolos exigidos pela Vigilância Sanitária e órgãos da saúde, entre outras.

\section{REFERÊNCIAS}

BALL, S. J.; MAINARDES, Jefferson (Orgs.). Políticas educacionais: questões e dilemas. São Paulo: Cortez, 2011.

BARROSO, J. Organização e Regulação dos Ensinos Básico e Secundário, em Portugal: sentidos de uma evolução Educ. Soc., Campinas, vol. 24, n. 82, p. 63-92, abril 2003.

BRASIL. Lei n. 9394 de 20 de dezembro de 1996. Estabelece as Diretrizes e Bases da Educação Nacional. Ministério da Educação e do Desporto. Brasília. 1996.

. Ministério da Educação e Cultura. Medida Provisória nº 934, de $1^{\circ}$ de abril de 2020.

Disponível em: https://abmes.org.br/arquivos/legislacoes/Medida-provisoria-934-2020-0401.pdf

. Lei $N^{o} 13.979$, de 6 de Fevereiro de 2020. Disponível:

http://www.in.gov.br/en/web/dou/-/lei-n-13.979-de-6-de-fevereiro-de-2020-242078735

. Ministério da Educação. Universidade Federal do Amazonas Pró-Reitoria de Ensino de Graduação-PROEG. Portaria de $n^{\circ} 31$, de 30 de abril de 2020. Disponível em https://edoc.ufam.edu.br/bitstream/123456789/3102/40/PORTARIA_PROEG_31_30_04_202 0AEE.pdf. Acesso em 26 maio 2020.

. Portaria de $n^{\circ} 36$, de 30 de maio de 2020. Disponível em

https://edoc.ufam.edu.br/bitstream/123456789/3102/47/NOVA\%20PORTARIA\%2036\%20A EE.pdf. Acesso em 26 maio 2020.

CHARLOT, B. Da relação com o saber - elementos para uma teoria. Porto Alegre: Editora Artmed, 2000.

CARVALHO, R. E. Removendo Barreiras para a aprendizagem. 4. ed. Porto Alegre: Mediação,2002.

CERTEAU, M. A invenção do cotidiano: 2. Morar, cozinhar. Petrópolis, Rio de Janeiro: Vozes, 2008. 
CIEB (2020). Planejamento das Secretarias de Educação do Brasil para Ensino Remoto. Disponível em: http://cieb.net.br/pesquisa-analisa-estrategias-de-ensino-remoto-desecretarias-deeducacao-durante-a-crise-da-covid-19/. Acesso em 22 maio 2020.

HEERDT, M. L.; COPPI. P. de. Como Educar Hoje? reflexões e propostas para uma educação integral. São Paulo: Mundo e Missão, 2003.

IBGE - INSTITUTO BRASILEIRO DE GEOGRAFIA E ESTATÍSTICA, 2019. Cidades IBGE, Disponível em : https://cidades.ibge.gov.br/brasil/am/panorama. Acesso em: 3 jun. 2020.

MÉSZÁROS, I.Para além do capital: rumo a uma teoria da transição. tradução Paulo Cezar Castanheira e Sérgio Lessa. São Paulo: Boitempo, 2002.

NOTA TÉCNICA. Análise: Ensino a Distância na Educação Básica Frente à Pandemia da COVID-19, 2020. Disponível:

https://www.todospelaeducacao.org.br/_uploads/_posts/425.pdf . Acesso em: 22 maio 2020.

PALMER, R. R. “Equality.” WIENER, Philip P. (ed.). Dictionary of the History of Ideas. New York: Scribner, 1973.

SANTOS, B. de S. A cruel pandemia do vírus. Editora Boitempo, 2020.

SHIROMA, E. O.; CAMPOS, R.F. La resignificación de la democracia escolar mediante el discurso gerencial: liderazgo, gestión democrática y gestión participativa. In: FELDFEBER, M. e OLIVEIRA, D.A (Orgs). Políticas educativas y trabajo docente: Nuevas regulaciones, \& Nuevos sujetos ¿ Buenos Aires: Centro de Publicaciones Educativas y Material Didáctico, 2006.

SODRÉ, M. Reinventando a cultura: a comunicação e seus produtos. Rio de Janeiro: Vozes, 1996.

SOUZA, J. C. R. de. A Geografia nas Escolas das Comunidades Ribeirinhas de Parintins: entre o currículo, o cotidiano e os saberes tradicionais. 2013. Tese (Doutorado em Geografia Física) - Universidade de São Paulo. São Paulo, 2013. Disponível em:

https://www.teses.usp.br/teses/disponiveis/8/8135/tde-08082013-

102213/publico/2013_JoseCamiloRamosDeSouza.pdf.Acesso em: 2 jun. 2020.

SPOSATI, Aldaíza. Mapa da exclusão/inclusão social. Comciência, n. 36, out. 2002.

Disponível em: Acesso em: 31jul. 2020.

TENTI FANFANI, E. Introducción: Mirar la escuela desde afuera. In:TENTI FANFANI, Emilio (Org.). Nuevos temas em la agenda de política educativa. Buenos Aires: Siglo XXI Editores, 2008. 
TURRA, C. M. G.; ENCONE, D.; SATÁNNA, F. M. Planejamento de ensino e avaliação. Porto Alegre: PUC - EMMA, 1975.

UNESCO. Declaração mundial sobre educação para todos. Plano de ação para satisfazer as necessidades básicas de aprendizagem. Tailândia. 1990.

VALENTE, J. A. O ensino híbrido veio para ficar. In: BACICH, L.; TANZI NETO, A.; TREVISANI, F. D. M. ...r;e 0: personalização e tecnologia na educação. Porto Alegre: Penso, 2015.

\footnotetext{
${ }^{i}$ Doutora em Educação. Professora Associada da Universidade Federal do Piauí e do Programa de PósGraduação em Educação. Docente da área de Fundamentos Políticos-Administrativos da Educação. Líder e pesquisadora do Núcleo de Estudos sobre Formação, Avaliação, Gestão e Currículo - NUFAGEC. Teresina-PI, Brasil. Contato: neidecguedes@hotmail. ORCID http://orcid.org/0000-0001-6801-3922

${ }^{\text {ii } M e s t r e ~ e m ~ E d u c a c ̧ a ̃ o . ~ P r o f e s s o r ~ A s s i s t e n t e ~ d o ~ I n s t i t u t o ~ d e ~ C i e ̂ n c i a s ~ E x a t a s ~ e ~ T e c n o l o ́ g i c a s ~-~ I C E T ~ d a ~}$ Universidade Federal do Amazonas. Membro e pesquisador do Núcleo de Estudos sobre Formação, Avaliação, Gestão e Currículo - NUFAGEC e do e do Grupo de Pesquisa em Educação, Formação e Ensino para a diversidade- GPEFED/ICET/UFAM. Itacoatiara-AM, Brasil. Contato: ti-pg@hotmail.com ORCID http://orcid.org/0000-0002-8324-3723

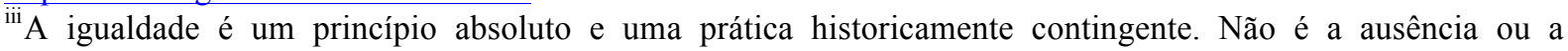
eliminação da diferença, mas sim o reconhecimento da diferença, ou seja, "[...] requer um ato de escolha, pelo qual algumas diferenças são minimizadas ou ignoradas enquantoque outras são maximizadas e postas a se desenvolver" (PALMER, 1973-74, p. 139)

${ }^{\text {iv }}$ A equidade é entendida como: [...] o reconhecimento e a efetivação, com igualdade, dos direitos da população, sem restringir o acesso a eles nem estigmatizar as diferenças que conformam os diversos segmentos que a compõem. Assim, equidade é entendida como possibilidade de as diferenças serem manifestadas e respeitadas, sem discriminação; condição que favoreça o combate das práticas de subordinação ou de preconceito em relação às diferenças de gênero, políticas, étnicas, religiosas, culturais, de minorias, etc. (SPOSATI, 2002, p. 5)

${ }^{v} \mathrm{Na}$ planilha do Subcomitê de Combate ao COVID-19 das unidades do interior da Universidade Federal do Amazonas (2020), disponível em: https://datastudio.google.com/u/0/reporting/d0802ebd-62a9-428c-89d8 c2a6989f2aacc/page/6zXD, você leitor(a) pode visualizar os cursos que não apareceram na figura.
} 